\title{
QUANTIFYING TOTAL CARBON STOCK OF MATURE OIL PALM
}

\section{KHO LIP KHOON*; ELISA RUMPANG*; NORMAN KAMARUDIN ${ }^{\star}$ and MOHD HANIFF HARUN}

\begin{abstract}
The carbon stock of oil palm is an important indicator of environmental and agronomical impact of oil palm. Measuring variations in oil palm biomass with age, geographical region, and plantation management are necessary to accurately predict carbon stock across ecosystems. However, quantification of total carbon stock for mature oil palms is not well described. Here, we determined above- and below-ground biomass of mature palms planted on mineral soil in Sarawak, Malaysia using both destructive and non-destructive methods. Based on allometric equations, older palms constitute a greater total carbon stock, with the largest contributions from trunks and roots. Total carbon stocks assessed per the non-destructive method were 50.7 $\mathrm{MgCha}{ }^{-1}, 44.4 \mathrm{MgCha}^{-1}$, and $72.1 \mathrm{MgCh}^{-1}$ in 11-year old, 21-year old, and 29-year old palms, respectively. Our results show that trunk biomass increases with the age of palms. Root biomass was substantially higher in older palms. Using the destructive method, total carbon stock of the 21-year old palms was approximately $51.3 \mathrm{MgC} \mathrm{ha}{ }^{-1}$. Differences between the two methods may be attributed to unaccounted palm components using the non-destructive method. The inclusion of unaccounted palm components, such as spears, cabbage and trunk bole would increase total carbon stock of 21-year old palms to approximately $48.0 \mathrm{MgC} \mathrm{ha-1}$. This suggests that the non-destructive method may effectively estimate carbon stock, given specific corrections and assumptions. This study demonstrates a field applicable approach for quantifying the total carbon stock of oil palm to assess the impact of oil palm plantation on the ecosystem carbon balance.
\end{abstract}

\section{Keyword: carbon stock, oil palm, biomass.}

Date received: 2 January 2019; Sent for revision: 3 January 2019; Received in final form: 2 April 2019; Accepted: 6 August 2019.

\section{INTRODUCTION}

Oil palm (Elaeis guineensis Jacq.) is a major economic crop that continues to expand rapidly across landscapes, covering the whole process chain while ensuring the oil palm industry meets sustainable goals (Kushairi et al., 2017; 2018). All palm oil and its products produced in Malaysia will come from sustainable sources and practices by 1 January 2020, reinforce Malaysia's commitment to responsible farming practices (Kushairi et al., 2017).

Malaysian Palm Oil Board, 6 Persiaran Institusi,

Bandar Baru Bangi, 43000 Kajang, Selangor, Malaysia.

E-mail: lip.khoon@mpob.gov.my
Comprehensive plantation carbon measurements are imperative to assess the long-term effects of plantation carbon balance on greenhouse gases in the atmosphere. There is currently unprecedented interest to explore the contribution of oil palm as a potential carbon sink (Henson, 1999; Germer and Sauerborn, 2007; Kho et al., 2011). The oil palm stores approximately $90 \%-96 \%$ of total annual dry production in the above-ground biomass as trunk, fronds, and bunches (Corley and Tinker, 2003; Kotowska et al., 2015). As such, the above-ground biomass is an important indicator of carbon budget of oil palm plantation. The management of oil palm plantation affects the carbon cycle mainly through the contribution of above-ground biomass 
components. Maintenance pruning of palms and continuous recycling of fronds contribute to annual dry matter production at approximately $10 \mathrm{Mg}$ $\mathrm{ha}^{-1} \mathrm{yr}^{-1}$ in the Ivory Coast (Hartmann, 1991). The standing stock of palms provides a semi-permanent carbon pool, which, depending on the alternative land uses, would otherwise enter the atmosphere.

Despite the importance of above-ground biomass, data is limited and the applicability of allometricequations remains to betested. Destructive sampling by felling palm is another method to estimate palm biomass but involves financial losses and is usually targeted at mature old palms to be replanted. In Malaysia, biomass estimation has been done using both non-destructive allometric equations and destructive methods to determine above- and below-ground biomass of 23-year old palms (Khalid et al., 1999a, b). The aim of this study is to quantify above- and below-ground biomass of mature palms on mineral soil. We will explore both destructive method and allometric equations to compare both methods to estimate total standing carbon stock of oil palm on mineral soil across a range of different-aged palms.

\section{MATERIAL AND METHOD}

\section{Study Site}

This study was carried out at an oil palm plantation, the Lambir Estate of Sarawak Oil Palms Berhad, in Lambir, Miri, Sarawak in Malaysia $\left(4^{\circ} 6^{\prime} \mathrm{N}\right.$, $113^{\circ} 59^{\prime} \mathrm{E}$ ) in 2013 (Figure 1). The total area of planted oil palm in Lambir Estate was approximately 4200 ha. The Lambir Estate is divided into Lambir 1
(2028.5 ha) and Lambir 2 (2192.02 ha), with oil palms planted between 1985 and 2002. The planting density was 136 palms ha $^{-1}$. Three 1 ha plots $(100 \mathrm{x}$ $100 \mathrm{~m}$ ) were established, one each on the area of oil palm planted in 1985 (LAMOP85), 1992 (LAMOP92), and 2002 (LAMOP02). The oil palm estate planted in 1992 was assessed using both non-destructive and destructive sampling, while the other two sites (1985 and 2002) were mainly assessed following nondestructive sampling. The mean annual rainfall was approximately $2630 \mathrm{~mm}$ between 2000 and 2010 . The mean annual temperature in Lambir estate for the period $2000-2010$ was $25.9^{\circ} \mathrm{C}$ with little seasonal variation (temperature and precipitation recorded from an $80 \mathrm{~m}$ tall canopy crane approximately $15 \mathrm{~km}$ away from Lambir Estate).

The soils in the Lambir Estate consist of sandstone and shale. The shale-derived soils are clay-rich udult Ultisols (Soil Survey Staff, 2006), with typically $40 \%$ sand and high water-holding capacity (Davies et al., 1998). The sandstone-derived soils are humult Ultisols (Soil Survey Staff, 2006), with high sand content (typically 68\% sand) and low waterholding capacity (Ashton and Hall, 1992; Davies et al., 1998). The topography of Lambir Estate ranges from hill ridges and terraces to low-lying alluvial areas or low basins. Hills covered approximately $60 \%$ of Lambir Estate (Wall, 1964). The soils and geomorphology of Lambir Estate have previously been described in detail (Wilford, 1961; Wall, 1964).

\section{Non-destructive Method}

All palms within the 1 ha sampling plot were tagged and numbered. The main components of oil palm were measured following the non-destructive

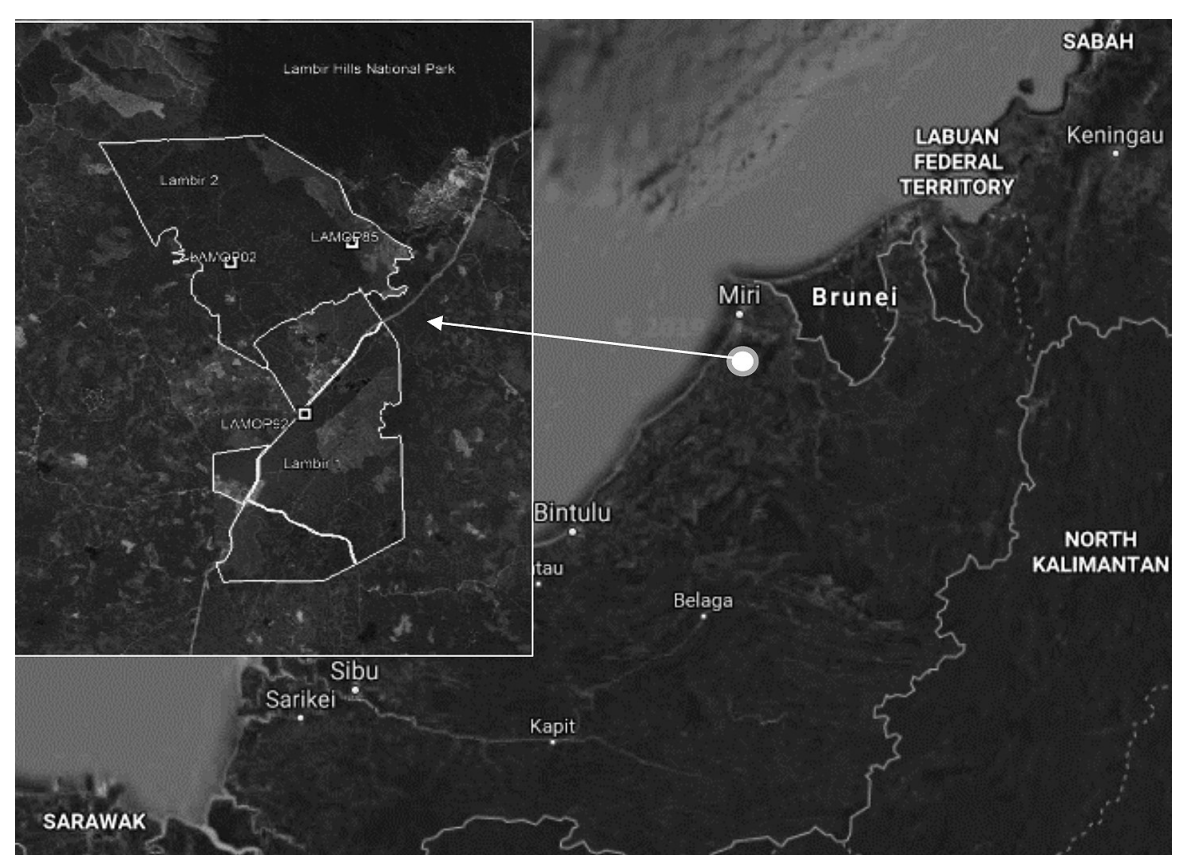

Figure 1. The study site in Lambir 1 Estate and Lambir 2 Estate near Miri, Sarawak. 
sampling method successfully employed and tested in previous studies (Corley et al., 1971; Corley and Tinker, 2003; Aholoukpè et al., 2013) dry weight of leaflets, dry weight of a fragment (length $=0.30 \mathrm{~m}$ ). Measurements were conducted mainly to determine the main oil palm biomass components, particularly trunk, frond, frond base, and root. In addition, epiphytes grown on frond bases of palms were measured. In this study, non-destructive sampling method refers to sampling of palm components without the need to destructively fell the whole palm.

Trunk. All palms were measured for diameter and height. Diameter was measured at $1.3 \mathrm{~m}$ from ground level using a large caliper. Using the laser rangefinder (Forestry Pro, Nikon Inc., USA), the height was measured at frond 41 or the $6^{\text {th }}$ frond in the first spiral (Zuraidah et al., 2017). Trunk biomass was estimated based on the allometric equation given by Corley and Tinker (2003):

$$
T=V S=\left(\pi r^{2} h\right) S
$$

(Equation 1)

where $T$ is the trunk dry weight $(\mathrm{kg}), V$ is the volume increment of the trunk ( $1 / \mathrm{yr}), h$ is the annual height increment, $r$ is the trunk radius, and $S$ is the density of dry trunk $\left(\mathrm{kg} \mathrm{litre}{ }^{-1}\right)$ :

$$
S=0.0076 t+0.083
$$

(Equation 2)

where $t$ is the age of palm in years from transplanting.

Frond. Frond biomass includes leaflets, rachis and petiole. Three mature fronds of 17, 21 and 25, following the phyllotaxis arrangement of fronds around the palm axis, were sampled from each palm. The length of rachis was measured, and a $30-\mathrm{cm}$ fragment was sampled mid-way along the rachis. Rachis fragment was dried in the oven at $80^{\circ} \mathrm{C}$ to constant weight. The mean biomass of an individual mature frond is estimated by the following equation given by Aholoukpè et al. (2013):

$$
\begin{aligned}
& M D W_{\text {mature frond }}=1.147+2.135 \times\left[1 / 3 \times\left(D W_{\text {rachis17 }}+D W_{\text {rachis21 }}\right.\right. \\
& \left.\left.+D W_{\text {rachis25 }}\right)\right]
\end{aligned}
$$

where $D W_{\text {rachis17, }} D W_{\text {rachis21, }}$ and $D W_{\text {rachis25 }}$ is the dry weight of rachis 12,21 , and 25 respectively. The dry weight of rachis was estimated based on the following equation given by Aholoukpè et al. (2013):

$$
\text { DWrachis }=1.133 \times \frac{D W_{\text {frag }}}{L_{\text {frag }}} \times L_{\text {rachis }} \quad \text { (Equation 4) }
$$

where $D W_{\text {frag }}$ is the dry weight of $30 \mathrm{~cm}$ fragment $\left(L_{\text {frag }}\right)$ of the rachis length $\left(L_{\text {rachis }}\right)$.
Frond base. Quantity of frond bases were calculated for each palm in the 1 ha plot. Frond bases were sampled within $0.5 \mathrm{~m}$ length around the palm at 1.3 $\mathrm{m}$ above-ground. The frond bases were separated into the following: i) complete frond base; and ii) fragments of frond base. Sub-samples were collected from each component, weighed, and dried to constant weight. The average frond base from these seven palms was extrapolated across all palms in 1 ha.

Root. Three triangular subplots were established among seven palms in the middle of each 1 ha plot following the design by Syahrinudin (2005) (Figure 2). Soil cores $(11 \mathrm{~cm}$ diameter, $60 \mathrm{~cm}$ length) were extracted to a depth of $60 \mathrm{~cm}$ from 16 systematic sampling points in each triangular subplot. All roots were extracted and separated from the $60 \mathrm{~cm}$ soil cores, washed, oven dried at $80^{\circ} \mathrm{C}$, and weighed.

Given that the extracted roots were estimated between 0 and $60 \mathrm{~cm}$ from the soil surface, we corrected the estimation up to $100 \mathrm{~cm}$ depth to reduce the discrepancies of root measured from different soil depths. The correction factor was calculated using the depth distribution of root biomass of a mature palm at the MPOB Research Station, Kluang, Johor (Khalid et al., 1999b). Root biomass was extrapolated up to $100 \mathrm{~cm}$ based on the following equation:

$$
\mathrm{W}_{\mathrm{R}}=0.4408 e^{-0.016 x} \quad \text { (Equation 5) }
$$

where $\mathrm{W}_{\mathrm{R}}$ is the dry mass of roots in $\mathrm{kg}$, and $x$ is the soil depth in $\mathrm{cm}$. Hence, the correction factor for soil depth between $0 \mathrm{~cm}$ and $100 \mathrm{~cm}$ was 1.298 .

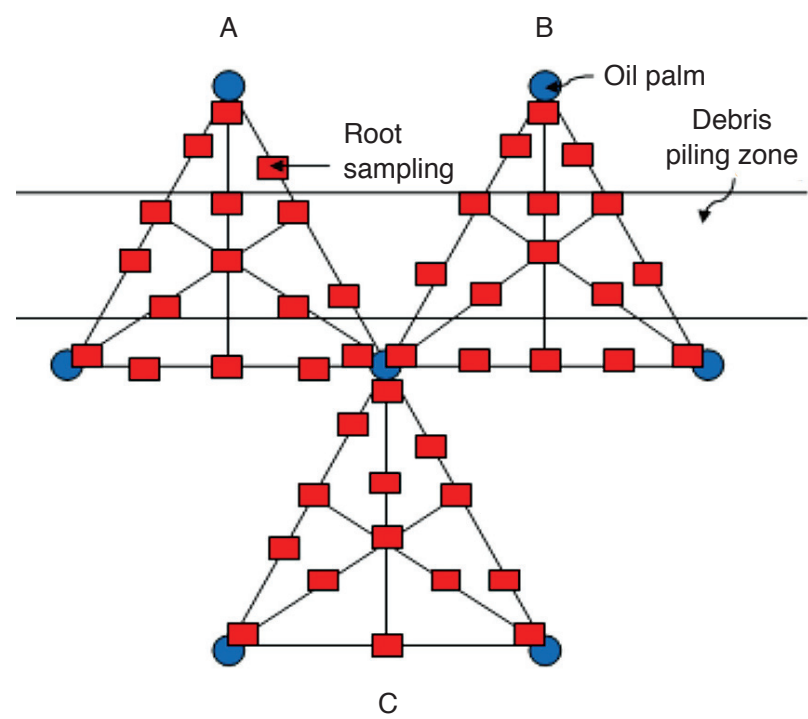

Figure 2. Triangular subplots established among seven palms in the middle of 1 ha plot following Syahrinudin (2005). Red square represents root sampling point, and blue circle denotes oil palm stand. 
Epiphytes. Epiphytes or climbers were sampled within $1 \mathrm{~m}$ around the palm at $1.3 \mathrm{~m}$ above-ground. Samples were dried in the oven at $80^{\circ} \mathrm{C}$ to constants weight. The average dry weight of epiphytes within $1 \mathrm{~m}$ was corrected following the height of each palm across 1 ha.

\section{Destructive Sampling}

Ten palms were randomly selected from the 21-year old plantation and felled (Figure 3). Each palm was carefully dissected and separated into the following components: i) trunk; ii) leaflets; iii) rachis; iv) petiole; v) frond base; vi) inflorescence; vii) spears; viii) cabbage; ix) trunk bole; $x$ ) root; $x i$ ) epiphytes; and xii) fruit bunch.

The fresh components were weighed in the field and sub samples of each component were weighed and dried to determine dry weights. Dried components were determined for $\mathrm{C}$ content for conversion factor from biomass to carbon. Specifically, the components of palms were treated following the procedure as follows:

1. Trunk - the trunk was divided equally into four sections. A sub sample of trunk ( $0.5 \mathrm{~m}$ fragment) was extracted from a randomly selected section, and further divided into eight parts. One-fourth was collected and dried to constant weight.

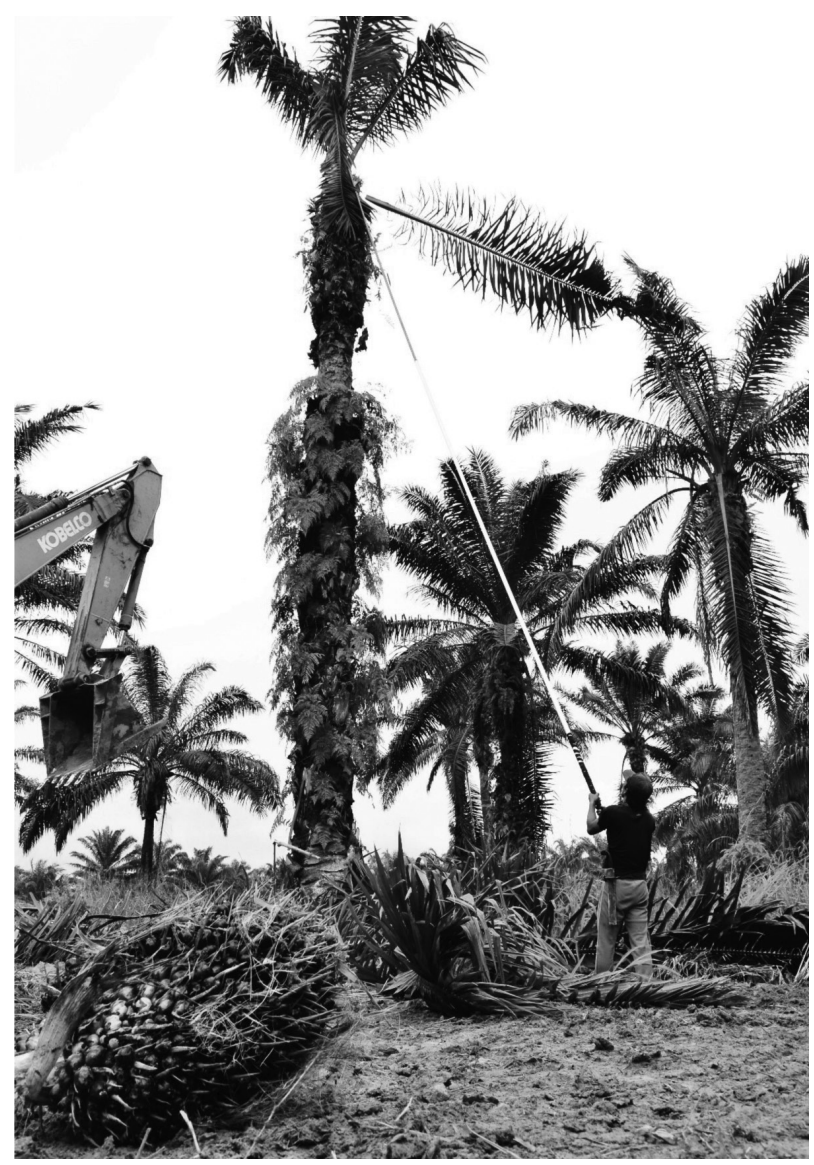

Figure 3. Each palm was randomly selected and felled, carefully dissected and separated in LAMOP92.
2. Leaflets / rachis / petiole / frond base / spears / cabbage/inflorescence / fruit bunch/epiphytes/ trunk bole - all samples were collected and fresh weights were recorded. Sub samples (oneeighth of the total fresh weight) were collected and oven dried to constant weight.

3. Root - a soil pit measuring $1 \times 1 \mathrm{~m}$ and up to a depth of $1 \mathrm{~m}$ was established for each palm. The extracted soils were sieved and separated for roots. All roots extracted were weighed and dried to constant weight.

\section{RESULT}

Total Standing Biomass following Non-destructive Method

In the 1 ha plot, the total number of palms assessed were 117, 112, and 130 in the 29-year old plantation, 21-year old plantation, and 11-year old plantation, respectively. However, we estimated total standing biomass based on the recommended planting density of 136 palms ha $^{-1}$. The average recorded diameter was $47.2 \pm 5.8 \mathrm{~cm}$ in the 29 -year old plantation, $51.2 \pm 5.5 \mathrm{~cm}$ in the 21-year old plantation, and $59.5 \pm 6.7 \mathrm{~cm}$ in the 11-year old plantation. The tallest palms averaged approximately $11.0 \pm 1.1 \mathrm{~m}$ in 29-year old plantation, followed by 21 -year old plantation with average height of $7.7 \pm 1.1 \mathrm{~m}$, and the lowest palms was in 11-year old plantation with an average height of $4.7 \pm 0.7 \mathrm{~m}$.

The total standing biomass was approximately 72.1 Mg C ha- ${ }^{-1}$, 44.4 $\mathrm{Mg} \mathrm{C}^{-1}$, and 50.7 $\mathrm{Mg} \mathrm{C}$ ha $^{-1}$ in LAMOP85, LAMOP92, and LAMOP02 respectively. The highest standing biomass for 29year old palms was largely due to trunk and root biomass. Our current data is similar to that reported in previous studies (Rees and Tinker, 1963; Corley et al., 1971; Syahrinudin, 2005) suggesting that trunk biomass increases with palm age and maybe more as a function of height, as observed in our study. The root biomass may not show any trend among the mature palms assessed, however we found a much greater root biomass in 29-year old and 11year old palms. This can be attributed to sampling techniques employed that may have included other roots (vegetative undergrowth) from various sampling points. Hence, the root biomass reported in this study should be treated and interpreted cautiously and the sampling technique requires further investigation or refinement. However, the root biomass reported for 21-year old palms is quite consistent to that reported previously in Malaysia (Corley et al., 1971).

As expected, the trunk biomass is relatively high in older palms in LAMOP92 and LAMOP85 than younger palms in LAMOP02 (11-year old). Both trunk and roots contributed equally large 
carbon for the 29-year old palms, suggesting that carbon is still allocated to these components in older palms (Corley et al., 1971). However, we found substantially lower root biomass for 21-year old palms both using destructive and non-destructive methods. This may be attributed to the health and conditions of the palms or to a smaller extend the progenies of palms planted.

\section{Total Carbon Stock of Oil Palm Following Destructive Method}

The average height of palms was approximately $8.3 \mathrm{~m}$, and ranged between 7.3 and $10.1 \mathrm{~m}$. The diameter of palms ranged between 39 and 64 $\mathrm{cm}$. Using the destructive method to weigh all components of oil palm, the total standing biomass of 21-year old palms was $51.3 \mathrm{Mg} \mathrm{C}^{-1}$ (Table 1). This is approximately $16 \%$ higher than those assessed using the non-destructive method in the same plot (LAMOP92) and age group. The disparity was explicitly due to unaccounted components including cabbage, spears, trunk bole and the larger amount of epiphytes found growing on the trunks of oil palms. The epiphytes were $0.2 \mathrm{Mg} \mathrm{Cha}^{-1}$ based on non-destructive method but were relatively higher with estimate of $2.1 \mathrm{MgC} \mathrm{Ca}^{-1}$ using the destructive method. This is mainly attributed to the abundance and the species of epiphytes. The average mass of epiphytes from the palms selected for nondestructive method was approximately $26.8 \pm 2.9$ $\mathrm{kg}$, while those selected for destructive method was about $38.4 \pm 25.4 \mathrm{~kg}$. Hence, there is a large variation of biomass of epiphytes between palms.

It is inevitable that some components were not assessed following inaccessibility to conduct measurements, particularly cabbage, spears and trunk bole. These components could only be measured when the palms were harvested. Based on destructive method, however, these components constitute approximately $3.5 \mathrm{Mg} \mathrm{C} \mathrm{ha-1.} \mathrm{If} \mathrm{these}$ missing components were included and assessed, the total standing biomass of palm following nondestructive method may add up to approximately $48.0 \mathrm{Mg} \mathrm{C} \mathrm{ha-1}$. The non-destructive method was $7 \%$ lower than destructive method. However, both methods yielded comparable results following careful assumptions and estimation.

\section{Comparing Total Carbon Stock of Oil Palm}

This study provided essential information on the standing biomass and total carbon stock of mature oil palm in Sarawak, Borneo region. In this study, we have assessed all components of oil palm to determine the total carbon stock of mature standing oil palm. However, certain components of oil palm are harvested and taken out from the oil palm system, or often not measured. These components, for example fruit bunch and epiphytes, are typically not included in estimations of total carbon stocks. Hence, considering the components typically assessed using destructive methods, our estimation is relatively higher than earlier studies conducted in Johor, Malaysia, but considerably lower than a recent study conducted in Sumatra, Indonesia (Table 2). The substantial differences are mainly attributed to the biomass of trunk and trunk bole. Larger trunk and trunk bole can be explained by the different progenies, soils, agronomic treatments, and environmental factors. Despite these differences, we believe that our results add to the knowledge on oil palm carbon stocks and the distribution of carbon in various oil palm components, including soil.

\section{RECOMMENDATION}

Regardless of the components measured and included in the estimation of total carbon stock, our results agree with previous studies (Kho and Jepsen, 2015). In addition, our results using both the non-

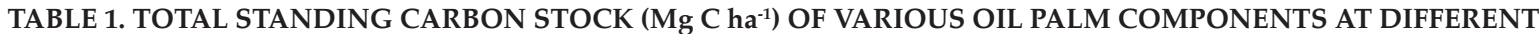
AGES BASED ON NON-DESTRUCTIVE AND DESTRUCTIVE SAMPLINGS CONDUCTED IN 2013

\begin{tabular}{|c|c|c|c|c|}
\hline \multirow{2}{*}{$\frac{\text { Sampling method }}{\text { Year planted (age) }}$} & \multicolumn{2}{|c|}{ Non-destructive } & \multicolumn{2}{|c|}{ Destructive } \\
\hline & 2002 (11 yr) & $1992(21 \mathrm{yr})$ & $1985(29 \mathrm{yr})$ & $1992(21 \mathrm{yr})$ \\
\hline Trunk & 14.3 & 23.8 & 30.7 & 25.6 \\
\hline Frond & 7.7 & 5.6 & 6.3 & 5.8 \\
\hline Frond base & 4.2 & 2.3 & 0.6 & 2.6 \\
\hline Cabbage/spears & - & - & - & 1.4 \\
\hline Inflorescence & $0.1^{*}$ & $0.1^{*}$ & $0.1^{*}$ & 0.1 \\
\hline Trunk bole & - & - & - & 2.1 \\
\hline Root & 22.5 & 11.0 & 31.9 & 10.0 \\
\hline Climber/epiphyte & 0.6 & 0.2 & 1.2 & 2.1 \\
\hline Fruit bunch & $1.3^{*}$ & $1.3^{*}$ & $1.3^{*}$ & 1.3 \\
\hline Others & - & - & - & 0.3 \\
\hline Total & 50.7 & 44.4 & 72.1 & 51.3 \\
\hline
\end{tabular}

Note: * Estimated based on destructive sampling, assuming that inflorescence and fruit bunch are invariant to the age of palm. 


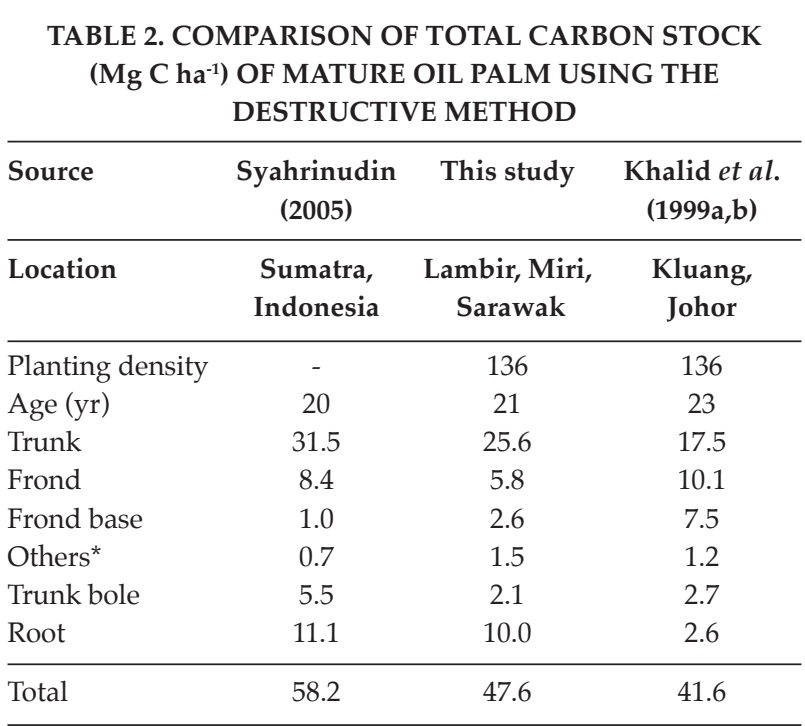

Note: * Others include spears, inflorescence and cabbage.

destructive and destructive methods have shown comparable total carbon stocks with appropriate corrections and assumptions particularly aboveground biomass. The root biomass using the nondestructive sampling techniques may require careful sampling protocol to avoid accounting for non-palm roots. We suggest using the nondestructive method to assess total carbon stocks of oil palm, in line with previous recommendations, e.g. perennial crops (Hardon et al., 1969; Corley et al., 1971). Such simple measurements and analyses, if widely conducted by the oil palm industries, could provide essential and accurate information on total carbon stocks or annual dry matter production of oil palm across various sites, soils, progenies and environment. From that point of view, it is imperative to obtain more quantitative data in order to estimate carbon balances more effectively and understand the contribution of oil palm as a carbon sink or source. In addition, comparative studies on changes in biomass and carbon stocks provide plausible answers to the impacts and implications of forest conversion to oil palm plantations.

\section{CONCLUSION}

Our study provides a detailed description of total standing carbon stock of mature oil palm. We find that the total carbon stock of older mature palms is the highest and that considerable biomass is allocated in the trunk and roots. The nondestructive and destructive methods are relatively consistent, however, corrections for unaccounted components of palms, sampling procedures, and careful assumptions are needed. The nondestructive method demonstrates a field applicable approach for quantifying total carbon stock of oil palm to assess the impact of oil palm plantation on the ecosystem carbon balance.

\section{ACKNOWLEDGEMENT}

The authors wish to thank the Director-General of MPOB for permission to publish this study. The financial support for this study was provided by MPOB. The author would like to thank the Sarawak Oil Palms Berhad for their permission to conduct this study in Lambir Estate. We thank Datuk Dr Choo, Y M; Dr Tan, Y A; Paul, W; Chua, K H; Pannirselvam, T; Zamani and Ben, A for their support. Badom, C; Manau, M; Steward, E S; Xyxtus, T; Jaapar, S; Nasir, M; Mahlel, $\mathrm{H}$ and Rengga, A for their field assistance.

\section{REFERENCES}

Aholoukpè, H; Dubos, B; Flori, A; Deleporte, P; Amadji, G; Chotte, J L and Blavet, D (2013). Estimating aboveground biomass of oil palm: Allometric equations for estimating frond biomass. Forest Ecol Manag Vol. 292: 122-129.

Ashton, P S and Hall, P (1992). Comparisons of structure among mixed dipterocarp forests of Northwestern Borneo. J. Ecol. Vol. 80(3): 459-481.

Corley, R H V; Hardon, J J and Tan, G Y (1971). Analysis of growth of the oil palm (Elaeis guineensis Jacq.). I. Estimation of growth parameters and application in breeding. Euphytica Vol. 20(2): 307-315.

Corley, R H V and Tinker, P B (2003). The Oil Palm. Fourth edition, Oxford, UK: Blackwell Science Ltd. 284 pp.

Davies, S J; Palmiotto, P A; Ashton, P S; Lee, H S and Lafrankie, J V (1998). Comparative ecology of 11 synpatric species of Macaranga in Borneo: Tree distribution in relation to horizontal and vertical resource heterogeneity. J. Ecol. Vol. 86: 662-673.

Germer, J and Sauerborn, J (2007). Estimation of the impact of oil palm plantation establishment on greenhouse gas balance. Environment, Development and Sustainability, 10: 697-716.

Hardon, J J; Williams, C N and Watson, I (1969). Leaf area and yield in the oil palm in Malaya. Exp. Agric. Vol. 5(01): 25-32.

Hartmann, C (1991). Evolution et comportement de sols sablo-argileux ferrallitiques sous culture de palmiers à huile. Cas de la plantation R. Michaux à Dabou (Côte d'Ivoire). Ph.D thesis. Université Pierre et Marie Curie, Paris. 
Henson, I E (1999). Comparative ecophysiology of oil palm and tropical rain forest. Oil Palm and the Environment: A Malaysian Perspective (Singh, G; Lim Kim Huan; Teo Leng and Kow, D L eds.). Malaysian Oil Palm Growers' Council. 277 pp.

Khalid, H; Zin, Z Z and Anderson, J M (1999a). Quantification of oil palm biomass and nutrient value in a mature plantation. I. Above-ground biomass. J. Oil Palm Res. Vol. 11(1): 23-32.

Khalid, H; Zin, Z Z and Anderson, J M (1999b). Quantification of oil palm biomass and nutrient value in a mature plantation. II. Below-ground biomass. J. Oil Palm Res. Vol. 11(1): 63-71.

Kho, L K; Alex Cobb and Mohd Haniff Harun (2011). The potential of oil palm in the global carbon cycle. Palm Oil Developments No. 54: 8-18.

Kho, L K and Jepsen, M (2015). Carbon stock of oil palm and tropical forest in Malaysia: A review. Singapore J. Trop. Geo. Vol. 36: 249-266.

Kotowska, M M; Leuschner, C; Triadiati, T; Meriem, S and Hertel, D (2015). Quantifying above- and belowground biomass carbon loss with forest conversion in tropical lowlands of Sumatra (Indonesia). Global Change Biology Vol. 21: 3620-3634.

Kushairi, A; Singh, R and Ong-Abdullah, M (2017). The oil palm industry in Malaysia: Thriving with transformative technologies. J. Oil Palm Res. Vol. 29(4): 431-439.
Kushairi, A; Loh, S K; Asman, I; Hishamuddin, E; Ong-Abdullah, M; Mohd Noor Izuddin, Z B; Razmah, G; Sundram, S and Ghulam Kadir Ahmad Parveez (2018). Oil palm economic performance in Malaysia and R\&D progress in 2017. J. Oil Palm Res. Vol. 30(2): 163-195.

Rees, A R and Tinker, P B H (1963). Dry-matter production and nutrient content of plantation oil palms in Nigeria. Plant and Soil Vol. 19(1): 19-32.

Soil Survey Staff (2006). Keys to Soil Taxonomy. $10^{\text {th }}$ edition, Washington,DC, USA: United States Department of Agriculture. 332 pp.

Syahrinudin (2005). The Potential of Oil Palm and Forest Plantations for Carbon Sequestration on Degraded Land in Indonesia (Vlek, P L G; Manfred, D; Christopher, M; Charles, R and Nick, V D G eds.). Gottingen: Cuvillier Verlag. 108 pp.

Wall, J R D (1964). Report on a Semi-detailed Soil Survey of Luak Experiment Station, $4^{\text {th }}$ Division, Sarawak. Kuching, Sarawak, Malaysia: Department of Agriculture, Sarawak.

Wilford, G E (1961). The Geology and Mineral Resources of Brunei and Adjacent Parts of Sarawak: With Description of Seria and Miri Oilfields. Borneo Region, Malaysia. Geological Survey, Brunei Press, Brunei. $319 \mathrm{pp}$.

Zuraidah, Y; Mazli, E; Salina, S; Hazira, H; Zulkifli, $\mathrm{H}$ and Haniff, M H (2017). Oil Palm Vegetative Measurements Manual. MPOB, Bangi. 35 pp. 